\title{
Continuous vs step change production process improvement as enablers for product redesign and new market opportunities
}

\author{
Geir Ringen $^{1}$ and Kjersti Øverbø Schulte ${ }^{2}$ \\ ${ }^{1}$ NTNU, Norwegian University of Science and Technology, Trondheim, Norway \\ geir.ringen@ntnu.no \\ ${ }^{2}$ SINTEF Raufoss Manufacturing, Trondheim, Norway \\ Kjersti.schulte@sintef.no
}

\begin{abstract}
Firms competing in global markets have to rapidly improve and innovate their products, processes, value chains and business models. Innovations can originate from a multitude of sources, where market needs and technology push are about the most common. However, company internal efforts towards incremental improvements of production processes can sum up to achieve breakthrough product innovations. This study focuses on the dynamic between process and product development, and bring about new knowledge on how systematic improvements of technological and organizational aspects related to manufacturing affects product innovation. We hypothesize that in global and mature markets and dispersed value chains the effect of mutual understanding and close collaboration between process- and product development can lead to breakthrough innovations at least as fast as by focusing on step change and disruptive process innovations. To explore this hypothesis we have conducted a case study, exploring two companies according to what we categorize as; the continuous improvement approach and the disruptive approach. Findings demonstrate that neither of the approaches necessarily respond to the everincreasing requirement to reduce time-to-market, but a set of barriers and enablers that together with contextual issues, supports step changes on products and processes.
\end{abstract}

Keywords: Exploration • Exploitation • Product redesign

\section{Introduction}

Increasing pressure to develop products of higher quality, with added functionality, at a lower cost, and in shorter time frames unquestionably brings about some dichotomies. The examples of high quality vs. low cost, less resources and time vs. higher performance, and increased robustness vs. lower weight all illustrate well known contradictions which become more and more important to balance and optimize. Only companies that can manage such conflicting objectives and in an adaptive manner consistently and timely bring new and innovative products to the market will be regarded as long-term partners. Advances in information and communication technolo-

adfa, p. 1, 2011.

(C) Springer-Verlag Berlin Heidelberg 2011 
gy, cross functional teams, overlapping processes, platform and module thinking, standardization of processes, and project management techniques have in various ways been introduced to keep up the pace of the product development process. However, implementations of such attempts have in many cases been only partial successful, suffering from lack of involvement and coordination. In this regard, Utterback [1] claimed that the main challenge is to develop the ability to innovate products, processes, and the organization, seeing them dependent of each other as a whole. This paper aims at investigate how company maturity affects the relation between processand product development and how this relation support levels of innovation.

\section{Theory}

A brief description of capabilities seen from three main approaches to product development are; the strategic viewpoint of Ansoff [2] and Porter [3, 4] which identifies product development as an instrument to achieve superior market positions, the firm level (see Prahalad and Hamel [5] and Wernerfelt [6]) which identifies resource utilization as a driving force behind successful product development and competitive advantage, and a third stream of literature, with contributors like Nelson and Winter [7] and Utterback [1], concluding that technological and organizational progress is driven by mechanisms of variation, selection, and retention.

Many firms will not see any dichotomies in these approaches; rather they will see them as a complementary mix of necessary focal areas at any given time. Another way to perceive these approaches is viewing the market-based perspective as rather static and outside-in focused, the resource-based as inside-out focused, whereas the evolutionary aspect adds dynamics to the whole. History shows that humans continuously have tried to polarise theories describing how we can improve the environment we are part of. Studies of society back in the 1950s sought to distinguish between the nature of social order and equilibrium on the one side and change and conflict on the other [8]. This order and conflict debate has been partly moderated, or as Burrell and Morgan (1979) put it; "outnumbered by order theorists". They also try to moderate the notion "order vs conflict" into the respectively terms regulation vs radical change. Theorists of the latter domain are concerned about finding explanations and drivers behind those justifying structural conflicts, contradictions, modes of domination, deprivation and radical changes, whereas followers of the regulation approach support the status quo, social order, consensus, social integration and system satisfaction. Transforming this philosophical and social theoretical distinctions into the domains of socio-technical studies and manufacturing management, we can argue that the following dimensions represent fundamentals and component characteristics of the regulation vs radical change perspective: Continuous improvement vs Innovation [9], Kaizen vs Kaikaku (process innovation) [10], Exploitation vs Exploration [11], Lean vs Radical innovation (step change) [12], and Stability vs Disruptive innovation [13].

Incremental innovation is characterized by a firm's current abilities to conduct small changes to its technological trajectory [14]. To achieve a continuous stream of such changes in a structured and strategic way initiatives such as lean production, Six 
Sigma and TQM have been extensively introduced in manufacturing organizations. The baseline for incremental innovation is standardized operational routines, in order to decrease variation and to discover performance gaps as opportunities for improvement. What these process management tools all have in common is that they seek to build capabilities for continuously and incremental innovations in operations [15]. A variant of incremental innovation is Continuous improvement, which is defined as "a systematic effort to seek out and apply new ways of doing work i.e. actively and repeatedly making process improvements" [16]. The main difference between these two approaches is that incremental innovation to some extent requires support from different organizational functions to be realized - whilst continuous improvement is something that can be initiated and realized at operational team level.

On the other hand, radical innovation is characterized by fundamentally changing the technological trajectory in an organization, and is often associated with searching and exploration, experimentation, risk and a break with the existing stock of knowledge. Hence, going in that direction requires exploratory efforts toward creating new competence and knowledge [14]. The goal of such an effort is mainly to develop new products/services that fulfils unspoken needs and wants in existing as well as new and emergent markets. This stream of literature is relatively sparse in having examples from process technology development and manufacturing industry in general, but Aylen describes such innovative activities with regards to new plants and the scrapping of old technology [17]. Traditional product development may have ingredients of radical innovation, at least in the fuzzy front where variants and alternatives are valuable input to a more structured process aiming at improve the properties and performance of a physical product [18]. Implications from such a process may be reengineering or modification of the manufacturing process.

Proponents of process management and incremental and continuous innovation argue that such a focus lead to organizational benefits as increased yields, less rework and waste, cost reductions and faster delivery times [16]. However, studies have shown that following a strategy entirely promoting incremental changes may over time suffer subsequent financial losses. One explanation for being trapped into such a situation is that by removing variation-increasing activities it also removes an organization`s ability to adapt outside its established technological trajectories [14]. By following a pure exploration strategy, the risk may aggregate to levels of threating the business so it may survive to reap the benefits of the investments [19].

A metaphor of ambidexterity has been coined by researchers to describe the ability of an organization to maintain dual attention on exploration and exploitation activities in order to survive and excel the present and secure the future. Managing this duality is a challenge as organizational structure, culture, activities, time span and activities all are elements of different nature, or contradictory at times, depending on degree of exploration and exploitation. However increasingly dynamic business environments forces organizations to pay attention to, and to balance both [20]. In its essence, the unknown have to be discovered or explored, and the known have to be exploited, to generate profit for the organization. Exploration involves activities such as search, variation, risk taking, experimentation, discovery, and innovation - and exploitation involves activities such as refinement, efficiency, selection, implementation, and exe- 
cution [11]. There are many elements dividing these two trajectories, indeed one important distinction is that exploration is said to rely on double-loop learning while exploitation involves single-loop learning [21].

In 1994 Utterback proposed that process and product innovation is interlinked, but could be differentiated into stages [1]. Thus an organization can balance the continuity and change in time, having long periods of consolidation combined with short periods of discontinuous change [22]. However, degree of organizational adaptation may be hampered by such an approach and it adds complexity to organizational structure and flexibility. Burgelman supposed a dynamic and autonomous strategy process to overcome the issue of flexibility and to solve the concept of organizational ambidexterity [23]. Similar thoughts are evident in discussions on static versus dynamic efficiency and leverage versus stretch [5]. The main conclusion from this discourse is that successful firms are engaged in two types of strategic activities, both for product and process development, which have different resource needs and outcomes.

\section{$3 \quad$ Method}

A case study is one of several ways of doing social science and understanding complex social phenomena, used in many situations to contribute to our knowledge of groups, organizations and related phenomena within a real life context [24]. Aase studies have become a very powerful research method, often dealing with a growing magnitude of changes over lesser and lesser time [25]. When conducting case studies construct validity it is important; to attain data that describes the phenomenon we are studying and that data can be separated from other phenomenon data [26]. External validity concerns how much can be generalized beyond the case itself. It is generally believed that multiple cases have a higher external validity than single cases.

This study includes two Norwegian case companies that we as researchers have followed in more than 5 years prior to writing this article. Our basis for empirical findings is observations, formal and unformal meetings, interviews and documents made available to us. The empirical data were categorized according to a model of the firms, see Fig. 1.

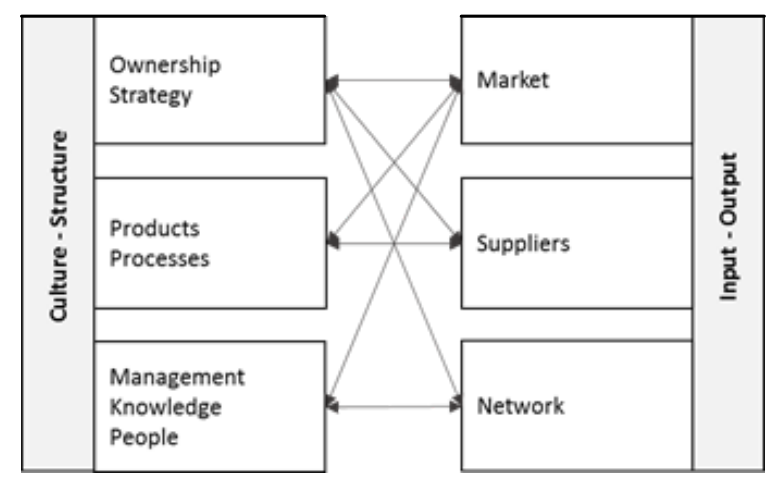

Fig. 1. Method for case studies. Intern factors in the left side, external factors on the right side. 
The model include internal and external factors. The internal factors are ownership, strategy, products and processes, management, knowledge and people, whereas external factors embrace market, suppliers and network. These factors are highlighted in the findings section below.

\section{$4 \quad$ Results}

\subsection{Case description}

Case A is a subsidiary of a multinational company developing and producing components and systems for utility vehicles. The company as a whole employs more than 10.000 employees and had in 2016 a revenue of about one billion USD across 30 production facilities globally. The case unit has about 240 employees.

Case B is a company which was established 8-9 years ago based on an idea of producing complex light weight parts by an innovative additive manufacturing process. The case company has today about 60 employees; all directed towards research and development activities to unleash the technology potential. The revenue stream is so far in the level of 1.5 million USD.

\subsection{Findings}

Case $\mathbf{A}$ is a supplier for the commercial vehicle market globally and is producing multi-material parts that must fulfill high demands on quality and safety. The production volume can be categorized as mass production, but the number of product variants are increasing so the production system is challenged by the flexibility criteria. Production is fully automated and the factory is designed to run unmanned for periods of time. Further, ambitions are to reduce cycle times and to produce according to zero defect manufacturing principles, where quality at an even larger extent has to be built into the product and the process to achieve in-line and real time quality control. These processes need to be interlinked through an automated component handling system, and each separate process needs to be reconfigurable to a new product variant within the timeframe of one cycle due to required flexibility and volume.

An interesting feature is that the case company in order to be an attractive and challenging workplace, has kicked-off a programme aiming at enabling operators, maintenance personnel and technicians to design and build next generation machines and equipment. The reasoning behind such a programme is that these resources have the best knowledge about existing capabilities and requirements, hence being able to convert these experiences into building robust machines producing zero defects. This new and integrative way of working aims to combine both technology utilisation and attractive work content, in line with the Industry 4.0 concept. Moreover, the company stresses high intellectual property on both products and processes. The manager has a long-term vision for the combined development efforts in the company. The approach for reaching the vision is sequentially working on very restricted, but critical technical tasks with regard to product and process, that combined will results in step changes to the product and might open new market opportunities. The company is organized as 
a relatively integrated product, process and production unit, but where support functions as product development, quality, and performance are reporting into a global matrix structure.

The main strategy for the subsidiary, among many others in the company, is to produce as cost effective, with outstanding quality, as possible to attract new and existing customers as well as internal positive attention towards receiving new investments and products to produce. The market is stable in the western world and growing in Asia, but the case company aims at taking a greater share of the existing market because their products support light-weight criteria in global environmental regulations. Network is important to the company, especially related to extend R\&D efforts. Numerous R\&D projects with external research institutes and universities have been carried out to improve products and processes combined. Additionally, the company representatives are nurturing direct and close relations to external experts; frequently receiving feedback on ideas and securing state of art knowledge. Collaboration with suppliers is also present, especially for developing critical tooling parts.

Case B is a company founded on an idea of producing complex light-weight parts by an innovative additive manufacturing process. Considerably research and development has been directed towards generating new knowledge about the specific and patented manufacturing process the last five years in order to scale up production to reach customer tact time. The new process aims at save time, cost and material usage throughout the extended value chain, and that rapidly and seamlessly can be configured to a broad portfolio of new products for different market applications. specially the transport sector and particularly the aerospace industry will benefit from successfully bringing this technology to an accepted readiness level. The market outlook views opportunities for a growing number of component variants, which needs to be met by flexibility in manufacturing and a set-up for frequent product introductions. Much effort is placed to industrialize the processes into a stable and repetitive production system. There are no or little room for launching product errors as a newcomer to a relatively conservative market for critical and structural components for use in for instance the aerospace industry. Thus, developing, utilizing and combining enabling technologies to create a zero defect manufacturing system is of crucial importance for a manufacturer of high-value, high-performance, and custom designed parts.

The knowledge base of the company is very strong in terms of formal education and experience, where a great number of the employees have a $\mathrm{PhD}$ or master degree. Extensive frontloading is to be found in the company, where near 60 employees are working on particular tasks as preparation for a product sales. The researchers and developers are organized into functional departments responsible for different parts of the value chain, where they have outlined a strategy for building an integrated value chain from raw material to finished products. From the relative short lifetime of the company and the ambitious goal, a more entrepreneurial or flexible organization might be expected.

The market demand for products from this process is expected to grow by $6 \%$ per year in the years to come, especially due to the high strength/weight ratio of the material. Developing a strong supplier base is not high on the agenda at the moment. The 
network is currently external $R \& D$ resources involved in improving material properties, critical processes, and manufacturing efficiency.

\section{$5 \quad$ Discussions and conclusion}

The first case company seeks innovation by summing up a number of continuous improvements and sequentially efforts of incremental innovation. These improvements are often combined product and process innovations, but each incremental step can occur in timely manner indicating that the time for realizing a breakthrough innovation in the market takes time. Company structure, core competence focus, performance, incitement systems and a considerably market maturity underpins that major innovations has to follow an incremental path. This is in line with Tushman, claiming that the focus on variation reduction and search for incremental improvements in routines, will lead to increased incremental innovation, exploiting existing capabilities [27]. The second case demonstrates that bringing a technology from a low to acceptable technology readiness level, at the same time as it intends to substitute a functioning and well-proven technology, is time and resource consuming. The capital needed is considerable and number of risk factors brings about an organization that focuses strongly on R\&D. For case B the outcome of the innovation process is intended to be breakthrough, still the process is very structured and contradictory to theories telling that such innovation journeys should take on a more explorative approach. Christensen and Overdorf argue that having the right resources in the early years of an organization is of the greatest importance, but when the organization matures capabilities shift more towards processes and values [28]. Thus, even though having the right resources a mature organization can have processes and values so powerful that it almost does not matter which people are assigned to which project. Analysing the innovation approach, whether continuous improvement or disruptive, based on an internal and external factor model demonstrates that neither of the approaches necessarily respond to the ever increasing requirement to reduce time-to-market in mature markets. This model can be supportive in defining contextual issues, barriers and enablers for innovation and guidelines for enabling the organization for bringing new products to the market in an ever-faster phase.

\section{References}

1. Utterback J (1994) Mastering the Dynamics of Innovation. Harvard Business School Press, Cambridge.

2. Ansoff HI (1965) Corporate Strategy. McGraw-Hill, New York.

3. Porter ME (1980) Competitive Strategy: Techniques for Analyzing Industries and Competitors. The Free Press, New York

4. Porter ME (1985) Competitive Advantage; Creating and Sustaining Superior Performance. The Free Press, New York.

5. Prahalad CK, Hamel G (1990) The Core Competence of the Corporation. Harvard Business Review. May-June, pp 79-91.

6. Wernerfelt B (1984) A Resource-based View of the Firm. Strategic Management Journal. 5, pp 171-180. 
7. Nelson RR, Winter SG (1982) An Evolutionary Theory of Economic Change. Harvard University Press, Cambridge.

8. Burrell G, Morgan G (1979) Sociological Paradigms and Organizational Analysis. Heinemann.

9. Womack JP, Jones DT, Roos D (1991) The Machine That Changed the World. HarperCollins Publishers, New York.

10. Yamamot Y (2010) Kaikaku in production. In School of innovation, design, and engineering, Mälardalen University: Västerås, Sweden.

11. March JG (1991) Exploration and Exploitation in Organizational Learning. Organization Studies. 2, pp 71-87.

12. Stringer R (2000) How to Manage Radical Innovation. California Management Review. 42(4), pp 70-88.

13. Christensen C, Horn M (2008) Disrupting Class: How Disruptive Innovation Will Change the Way the World Learns. McGraw-Hill, New York.

14. Benner MJ, Tushman ML (2003) Exploitation, Exploration, and Process Management: The Productivity Dilemma Revisited. Academy of Management Review. 28(2), pp 238-256.

15. Bessant J, Caffyn S, Gallagher M (2001) An Evolutionary Model of Continuous Improvement Behaviour. Technovation. 21, pp 67-77.

16. Anand G, Ward P, Tatikonda M, Shilling D (2009) Dynamic capabilities through continuous improvement infrastructure. Journal of Operations Management. 53(3).

17. Aylen J (2013) Stretch: How innovation continues once investment is made. R\&D Management. 43(3), pp 271-287.

18. Lager T (2011) Managing Process Innovation - From Idea Generation to Implementation. Imperial College Press, London.

19. Chesbrough H, Vanhaverbeke W, West J. (2006) Open Innovation: Researching a New Paradigm. Oxford University Press, Oxford.

20. Sinha, S. (2015) The Exploration-Exploitation Dilemma: A Review in the Context of Managing Growth of New Ventures. Vikalpa, 40(3), pp 313-323

21. Gupta KS (2008) A Comparative Analysis of Knowledge Sharing Climate. Knowledge and Process Management. 15(3), pp 186-195.

22. Tushman ML, Romanelli E (1985) Organizational evolution: A metamorphosis model of convergence and reorientation. Research in Organizational Behavior. 7, pp 171-222.

23. Burgelman RA (2002) Strategy is Destiny: How Strategy-making Shapes a Company's Future. Free Press, New York

24. Yin RK (2003) Case Study Research: Design and Methods. Sage Publications, Thousand Oaks.

25. Voss C, Tsikriktsis N, Frohlich M (2002) Case Research in Operations Management. International Journal of Operations \& Production Management, 22(2), pp 195.

26. Leonard-Barton D (1990) A Dual Methodology for Case Studies: Synergistic use of a Longitudinal Single Site with Replicated Multiple Sites. Organization Science, 1(1), pp 248-266.

27. Tushman M et al. (2003) Innovation streams and ambidextrous organizational designs: On building dynamic capabilities. Division of Research, Harvard Business School.

28. Christensen CM, Overdorf M (2000) Meeting the challenge of disruptive change. Harvard business review. 78(2), pp 66-77. 